\title{
Multiple Smart Home Controlling System using Database Replication Method
}

\author{
Wibowo Harry Sugiharto ${ }^{1}$, Muhammad Imam Ghozali ${ }^{2}$, Alif Catur Murti ${ }^{3}$, \\ Ratih Nindyasari ${ }^{4}$, M.Malik Hakim ${ }^{5}$ \\ \{wibowo.harrys@umk.ac.id¹, imam.ghozali@umk.ac.id², alif.catur@umk.ac.id ${ }^{3}$ \} \\ Department of Informatics Engineering, Faculty of Engineering, Universitas Muria Kudus, \\ Kudus - Indonesia ${ }^{12345}$
}

\begin{abstract}
The smart-house technology aims to increase home automation for personal comfort, security, and reduced energy consumption. The approach that has been done is direct control over smart home devices, this approach needs fixed IP. Unfortunately to use fixed IP need expensive cost. and in the case of multiple smart homes, it also makes multiple expensive costs. This paper purpose the method to create a smart home controlling and monitoring system with lower cost, and in the case multiple smart homes cost still not grow up. This paper purpose new approach with using database replication. The Result of this research is can make online multiple smart homes, and easy to access with HTTP and www.
\end{abstract}

Keywords: multiple smart home; controlling system; database replication.

\section{Introduction}

Smart home or called a smart house is a home that combines an advanced automation system to provide the inhabitants with sophisticated monitoring and control over the building's functions. For example, a smart home may control lighting, temperature, multi-media, security, window and door operations, as well as many other functions. Nowadays, the smart home is the integration of technology and services through home networking [1][2][3], using smart home technology then easily do online home controlling [4][5][6][7][8]. To make online home controlling, smart home need equip with the hardware such as a microcontroller, sensor, and actuator [4][9][10][11]. so the home can do remote control [12][13] and act intelligent monitoring [14] from the remote location. A major focus in technology of smart home is security [15][16] , personal comfort [6][17][18][19], and energy conservation [19][20][21][22].

The approach that has been done is direct control over smart home devices [23][24][25], the solution can apply the direct control is using fixed IP. But using DDNS [26] should provide extra cost, especially cost for remote control. This paper purpose to the new approach of using database replication. Database replication is made replicas of a user and synchronizes with the Design Master on a network server[27].

With this approach we can control and monitor multiple smart home server on single web services, also it can easy to access from the remote location using www on HTTP services. 


\section{The concept of Replication}

Represents the process of sharing information to ensure consistency between redundant resources. database replication is the same store on multiple storage devices, or computation replication if the executed many times. Replication represents the process of sharing information to ensure consistency between redundant resources. data replication is the same data stored on multiple storage devices, or computing replication if the same computing task is executed many times.

Database replication is the duplicate process on multiple instances of the same database and the process of sharing data or database design changes between databases in different locations [27].

\section{Non-Direct Multiple Smart Home Controlling Method}

\subsection{Smart home database replication}

This paper is a purpose to use database replication method for smart home controlling and monitoring system. The concept is how the smart home server gets the command from the user.

This method is reverse from direct controlling, also know by the non-direct controlling system. A smart-home server gets a command from the local database, and local database makes sharing data or duplicates database data from the online database, in the online database user make command and keep that command data in the online database. It is Show in Fig 1.

\subsection{Smart home non-direct controlling approach}

Non-Direct Controlling is the user not directly control smart home, but user need to change the online master database, that master database will synchronize to the local database, and the local database gets the command controlling from a user. It's Show in Fig 2 and Fig 3.

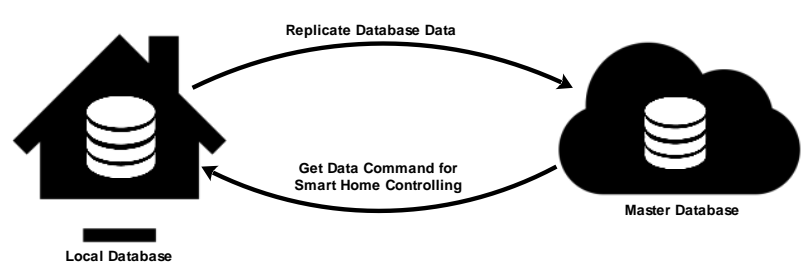

Fig. 1. Smart home database replication.

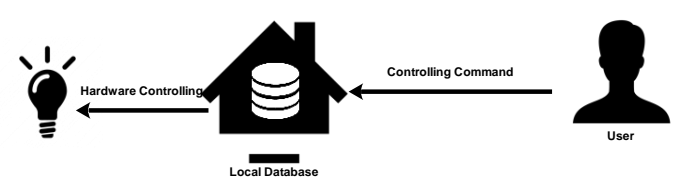

Fig. 2. Direct smart home controlling. 


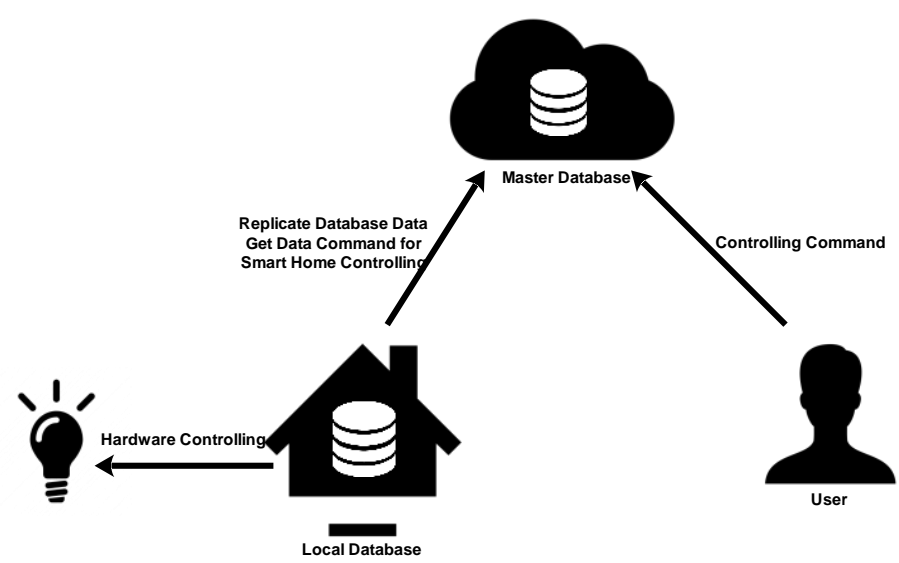

Fig. 3. Non-direct smart home controlling.

\subsection{Multiple Smart Home Server Controlling}

With the concept of database replication, its cheaps and easy to make multiple smart homes going online, every smart home will give the different id. So the user can access smart home separately using a single online master database. It will save much cost because just need a single online database. It's Show in Fig 4.

\section{Multiple Smart Home Controlling System Implementation}

Implementation of the Multiple Smart Home Controlling System is applied to web-based applications using PHP Web Programming and MySQL Database. this application creates permission for each user to control their own smart home. It's shown in Fig.5 and Fig.6.

From the login page, we should insert a username and password. If the username and password correctly, so we can enter the monitoring control form. Figure 6 is the controlling and monitoring page that used to look condition status port ON or OFF. There is eight port on the controlling and monitoring page and we can monitor the status port of the electronic equipment. 


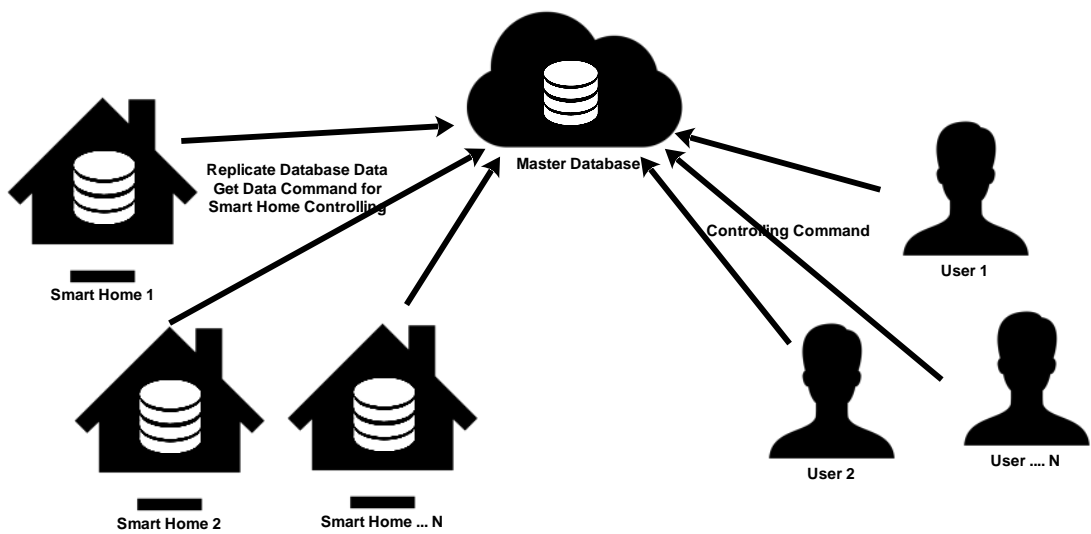

Fig. 4. Multiple smart home server controlling system.

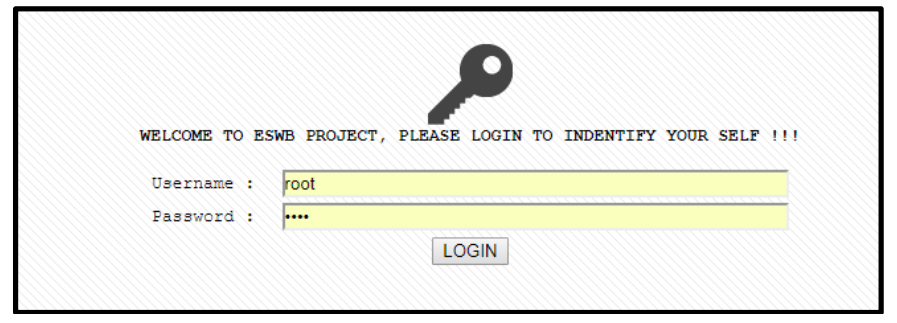

Fig. 5. Login page.

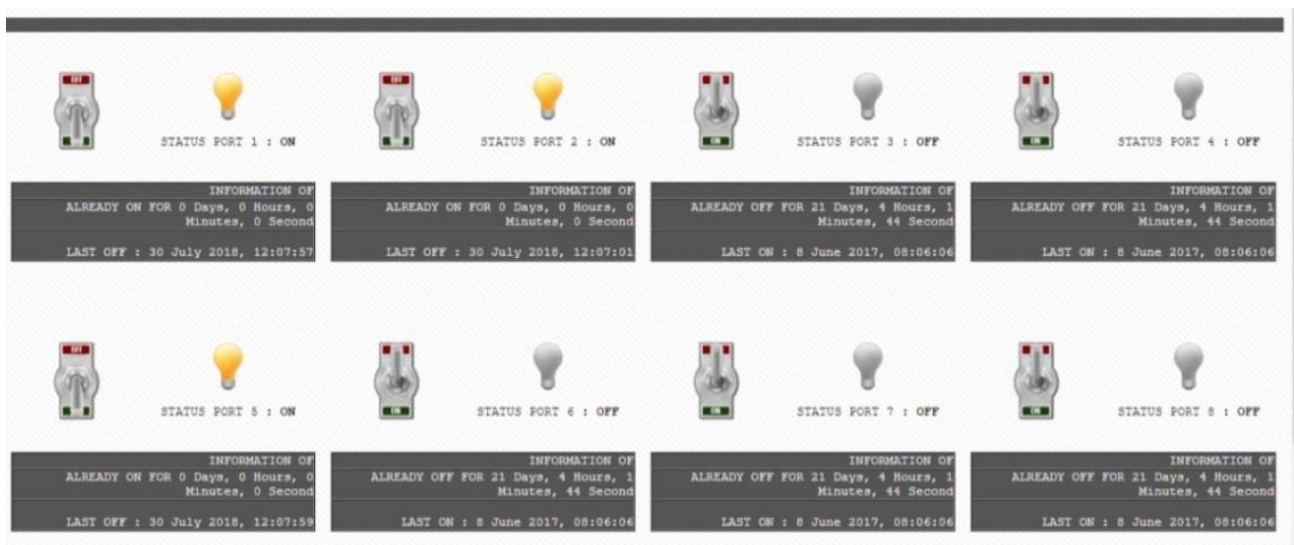

Fig. 6. Controlling and monitoring page. 
The first port can be used for the first electronic equipment, and the second status port can be used for other electronic equipment. Next, we can click ON or OFF on the switch. The handle switch on the down position so-called ON. In Fig. 6 down position have a green color. The handle switch on the up position is indicated OFF and have a red color. The switch that has a status port $=\mathrm{ON}$ can imagine with the yellow lamp, and the opposite status port is OFF, describe with the white lamp. In this page, we can read any information such as long days of the post already $\mathrm{ON}$ and so information about when the port was OFF. example base on the Fig. 6 on status port $1=\mathrm{ON}$, and the information of already $\mathrm{ON}$ for 0 days, 0 hours, 0 minutes dan 0 seconds. And the last OFF on $30^{\text {th }}$ July 2018, at 12:07:57.

\section{Conclusion}

From the result of implementation Multiple Smart Home Controlling System, that's system can perform to online controlling hardware, controlling multiple smart homes can online simultaneously. With a single online database on web services. And make user easy to access with HTTP protocol. This method had a weakness is local database server must access the online database continues every second to checking data change on the online database. Another weakness is if the online database is had a problem, it directly influence all smart home controlling system.

\section{References}

[1] R. Kadam, P. Mahamuni, and Y. Parikh, “Smart Home System,” Int. J. Innov. Res. Adv. Eng., vol. 2, no. 1, pp. 2349-2163, 2015.

[2] T. Mendes, R. Godina, E. Rodrigues, J. Matias, and J. Catalão, Smart Home Communication Technologies and Applications: Wireless Protocol Assessment for Home Area Network Resources, vol. 8, no. 7. 2015.

[3] F. Ding, A. Song, E. Tong, and J. Li, "A Smart Gateway Architecture for Improving Efficiency of Home Network Applications,” J. Sensors, vol. 2016, 2016.

[4] S. Suresh, H. N. S. Anusha, T. Rajath, P. Soundarya, and S. V. P. Vudatha, "Automatic lighting and Control System for Classroom," Proc. 2016 Int. Conf. ICT Business, Ind. Gov. ICTBIG 2016, 2017.

[5] S. Singh et al., "Home Automation and Internet of Things," Int. Adv. Res. J. Sci. Eng. Technol., vol. 3 , no. 6 , pp. 155-159, 2016.

[6] a J. Jara, M. a Zamora-Izquierdo, and a F. Skarmeta, "Interconnection Framework for mHealth and Remote Monitoring Based on the Internet of Things," Ieee J. Sel. Areas Commun., vol. 31, no. 9, pp. 47-65, 2013.

[7] M. Butt, M. Khanam, A. Khan, and M. S. H. Khiyal, "Controlling Home Appliances Remotely through Voice Command,” Int. J. Adv. Comput. Sci. Appl., vol. 48, no. 17, pp. 35-39.

[8] S. Palaniappan, N. Hariharan, N. T. Kesh, V. S. Cse, A. Deborah, and S. Assistant, "Home Automation Systems -A Study,” Int. J. Comput. Appl., vol. 116, no. 11, pp. 975-8887, 2015.

[9] S. Dengler, A. Awad, and F. Dressler, "Sensor / Actuator Networks in Smart Homes for Supporting Elderly and Handicapped People,” 21 st Int. Conf. Adv. Inf. Netw. Appl. Work., 2007.

[10] H. Ghayvat, S. Mukhopadhyay, X. Gui, and N. Suryadevara, "WSN- and IOT-based smart homes and their extension to smart buildings," Sensors (Switzerland), vol. 15, no. 5, pp. 10350-10379, 2015. [11] Q. Sun, W. Yu, N. Kochurov, Q. Hao, and F. Hu, "A Multi-Agent-Based Intelligent Sensor and Actuator Network Design for Smart House and Home Automation," J. Sens. Actuator Networks, vol. 2, no. 3, pp. 557-588, 2013. 
[12] R. Shahriyar, E. Hoque, S. M. Sohan, I. Naim, M. M. Akbar, and M. K. Khan, "Remote controlling of home appliances using mobile telephony," Int. J. Smart Home, vol. 2, no. 3, pp. 37-54, 2008.

[13] A. D, N. S. Mubina, and B. P, "Smart Home Automation Control Using Bluetooth And GSM," Int. J. Inf. Futur. Res., vol. 2, no. 8, pp. 2547-2551, 2015.

[14] C. González García, D. Meana Llorián, C. Pelayo G-Bustelo, and J. M. Cueva-Lovelle, "A review about Smart Objects, Sensors, and Actuators," Int. J. Interact. Multimed. Artif. Intell., vol. 4, no. 3, p. 7, 2017.

[15] H. Lin and N. Bergmann, "IoT Privacy and Security Challenges for Smart Home Environments," Information, vol. 7, no. 3, p. 44, 2016.

[16] D. C. Lévy-Bencheton, M. E. Darra, M. G. Tétu, D. G. Dufay, And D. M. Alattar, Security and Resilience of Smart Home Environments, vol. 153, no. December. 2015.

[17] R. Y. M. Li, "The usage of Automation System in Smart Home to provide a Sus- tainable Indoor Environment : A Content Analysis in Web 1. 0,” Int. J. Smart Home, vol. 7, no. 4, pp. 47-60, 2013.

[18] O. Bingol and K. Tasdelen, "Web-based Smart Home Automation: PLC- controlled Implementation," Acta Polytech. Hungarica, vol. 11, no. 3, pp. 51-63, 2014.

[19] A. S. Dicarlo, "Smart Homes--home automation," Livable New York Resour. Man., pp. 1-8, 2011. [20] I. I. I. Attia, H. Ashour, E. Inji, I. I. I. Attia, and P. Hamdy, "Energy Saving Through Smart Home," Online J. Power Energy Eng., vol. 2, no. 3, pp. 223-227, 2011.

[21] R. Panna, R. Thesrumluk, and C. Chantrapornchai, "Development of Energy Saving Smart Home Prototype,” Int. J. Smart Home, vol. 7, no. 1, pp. 47-66, 2013.

[22] W. H. Sugiharto, M. I. Ghozali, T. Infromatika, U. M. K. Kudus, "Online Electronic Devices Monitoring System Menggunakan Rule Based System,” J. Mantik Penusa, vol. 21, no. 1, pp. 21-25, 2017.

[23] S. Kumar, "Ubiquitous Smart Home System Using Android Application," Int. J. Comput. Networks Commun., vol. 6, no. 1, pp. 33-43, 2014.

[24] M. A. E.-L. Mowad, A. Fathy, and A. Hafez, "Smart Home Automated Control System Using Android Application and Microcontroller," Int. J. Sci. Eng. Res., vol. 5, no. 5, pp. 935-939, 2014.

[25] T. Hargreaves et al., "Smart homes, control and energy management: How do smart home technologies influence control over energy use and domestic life ?," Eur. Counc. an Energy Effic. Econ. 2015 Summer Study Energy Effic., pp. 1021-1032, 2015.

[26] K. Lin and Z. Jiang, "Using a Dynamic Domain Name System ( DDNS ) Technology to Remotely Control a Building Appliances Network,” Proc. Int. MultiConference Eng. Comput. Sci. 2017, vol. I, pp. 15-18, 2017.

[27] M. C. Mazilu, “Database replication,” Database Syst. J., vol. 1, no. 2, pp. 33-28, 2010. 